\title{
INTERLEUKIN RESPONSE IN CARDIOVASCULAR DISEASES: AN OVERVIEW
}

\author{
Mariya Negreva ${ }^{1}$, Svetoslav Georgiev ${ }^{1}$, Katerina Vitlianova ${ }^{2}$ \\ ${ }^{1}$ Department of Cardiology, Medical University of Varna \\ ${ }^{2}$ Clinic of Cardiology, Second City Hospital, Sofia
}

\begin{abstract}
Interleukins are important modulators of the immune response in the human body, which inevitably makes them participants in the intimate mechanisms of various diseases. Cardiovascular morbidity and mortality is high in the world as a whole, despite the ongoing primary and secondary prevention. Therefore their pathogenetic mechanisms are of significant research and clinical interest. A number of studies demonstrated changes in the interleukin status of patients with coronary heart disease, heart failure, some cardiomyopathies and rhythm conduction disorders. Significantly altered levels of basic for the immunity pro-inflammatory and anti-inflammatory cytokines were found. It was even proven, that some of them have predictive value for the manifestation of certain diseases. All this is a reason to allow interleukins to take part in the intimate mechanisms of cardiovascular diseases and consider the place of interleukin blockers in the treatment of these diseases.
\end{abstract}

Keywords: interleukins, inflammation, cardiovascular diseases

\section{INTRODUCTION}

\section{Interleukins}

Cytokines are signaling molecules, which by their nature are proteins or glycoproteins, secreted by specific cells of the immune system. Depending on their functions, type of secreting cells or purpose of action, cytokines are divided into interleukins, lymphokines and chemokines.

Address for correspondence:

Mariya Negreva, $M D, P h D$

First Clinic of Cardiology,

University Hospital "St. Marina",

1 Hristo Smirnenski blvd,

9010 Varna, Bulgaria

e-mail:mnegreva@abv.bg

Received: May 04, 2015

Accepted: June 12, 2015
For the first time the term "interleukins" (ILs) was introduced in the medical literature in 1979 (1). ILs represent a large group of secreted proteins, which play an essential role in the communication between leukocytes and that is where their name derives from. They usually act in a paracrine or autocrine manner, binding with high affinity to specific for them receptors. Target cells respond to ILs stimulation through new mRNA and protein synthesis (2).

ILs perform growth, differentiation and activation functions, which to a significant degree regulate and determine the strength and duration of the immune response (3). Therefore they have complex and substantially significant immunomodulatory as well as pro-inflammatory and anti-inflammatory effects (4).

It is well known that the fundamental response of innate immunity is inflammation, which protects the human body in case of infection and/or tissue 
damage. Its manifestation, both on a local as well as system level, is determined precisely by the interleukins - its important modulators.

\section{Inflammation in cardiovascular diseases}

A number of cardiovascular diseases are associated with inflammation. It contributes significantly to the pathophysiology of the coronary artery disease, given that the inflammatory cascade is at the base of the atherosclerotic process (5). The importance of inflammation is also established in the manifestation of heart failure (6), some cardiomyopathies $(7,8)$ and rhythm disorders (9). Given the regulatory and coordinating function that ILs exercise over the inflammation process, the interleukin balance represents a special research interest.

\section{INTERLEUKINS AND CARDIOVAS- CULAR DISEASES: THE FACTS}

An immunohistochemical study found increased levels of IL-1 $\beta$ protein in the wall of atherosclerotic coronary arteries, such as the rate of increase was proportional to atherosclerotic changes (10). In serum of patients with ischemic heart diseases, interleukin levels are also elevated. IL- $1 \beta$ is the dominant circulating isoform of IL-1. It has an expressed proinflammatory effect and once released can exert its effects both locally and systemically. The role of IL$1 \beta$ in the inflammatory response is a leading one and the enhanced values of the indicator are associated with presence of inflammation.

IL-6 also shows higher levels in patients with stable acute coronary syndrome compared to those measured in clinically stable angina pectoris (11). It, and its soluble receptor (IL-6R), are central regulators of the inflammatory process. They activate inflammation by stimulating B-cell differentiation, Tcell growth and induce the hepatic synthesis of CRP (12). In a study of Blankenberg et al. acute coronary events are associated with elevated levels of another interleukin, namely IL-18 (13).

In essence it is a pleiotropic pro-inflammatory cytokine that plays a main role in the inflammatory cascade. It stimulates the interferon- $\gamma$ production from T-lymphocytes and NK-cells, which are said to be the main cause for atherosclerotic plaque rupture. In the same study, statistical analysis shows that increased levels of the indicator are an indepen- dent predictor of manifestation of ischemic heart disease (IHD) in a population of healthy, middle-aged European men. IHD is also characterized by elevated levels of IL-8 and IL-12 (14). The main effector functions of IL- 8 are associated with activation of neutrophils into the sites of infection or tissue damage (15). Moreover, IL-8 has the ability to attract NK cells, T cells, basophils, and GM-CSF-primed or IL3-primed eosinophils. IL-12, like IL-8, exhibits proinflammatory effects by inducing proliferation, cytotoxicity and cytokine production by NK-cells. According to a survey by Vaddi et al. patients with stable and unstable angina pectoris have elevated levels of TNF- $\alpha$ and IFN- $\gamma$ compared to controls without coronary atherosclerosis (16). IFN- $\gamma$ is produced by cells of the innate (NK cells, macrophages, etc.) and acquired (cytotoxic $\mathrm{T}$ lymphocytes, $\mathrm{B}$ cells and the like) immunity and together with TNF- $\alpha$ has expressed pro inflammatory properties. The established in this study elevated levels are indicative of changes in the interleukin balance in patients with stable and unstable angina pectoris. A study by Eid et al. on atherosclerotic coronary arteries shows increased production of other two cytokines IL-17 and IFN- $\gamma$ (17). The obtained results are evidence of synergism of these cytokines and induction of pro-inflammatory response in smooth muscle cells of coronary vessels. In their study Abdulkareem et al. establish impaired interleukin balance in patients with AMI and unstable angina pectoris, due to elevated levels of pro-inflammatory IL- 8 and reduced values of anti-inflammatory IL-10 (18). Inflammation not only plays a fundamental role in the development of atherosclerosis and IHD, respectively, but is also related to the manifestation of early or delayed complications of the disease. For example, in patients with AMI and successful PTCA, serum concentrations of IL-10 are higher among patients who did not develop heart failure as a complication of AMI (19). It is known that IL-10 has pronounced anti-inflammatory properties and the ability to inhibit the synthesis of a number of pro-inflammatory cytokines. Its high values, established in the abovementioned study, suggest the protective effect of IL-10 on the myocard in ischemia, reperfusion, or both. In heart failure changes in IL- 8 and TNF- $\alpha$ were observed. In a study by Nymo et al. in patients with chronic heart failure 
Mariya Negreva, Svetoslav Georgiev, Katerina Vitlianova

(CHD) with adverse effect these indicators were significantly elevated (20).

It is known that secretion of ILs is induced not only by micro-organisms, but also by mechanical stimuli such as pressure or volume overload. Inflammatory fibrosis is a distinctive feature of both myocarditis and CHF. IL-4 is a TH2 type anti-inflammatory cytokine that inhibits the pro-inflammatory response of TNF- $\alpha$, IL-1 and IL-6. Simultaneously it has expressed pro-fibrotic properties by activating the synthesis of collagen type I and type II from the fibroblasts and stimulates fibrosis (21).

A study conducted on patients with CHF and hypertensive cardiomyopathy found elevated levels of IL-4 and pro-inflammatory IL-6. Straight correlation of these indicators with procollagen type III levels gives the authors a reason to accept the presence of an activated inflammatory process that takes part in the collagen metabolism (22). In stable heart failure NYHA functional class II-IV Naito et al. establish an increase in two other pro-inflammatory factors, namely IL-18 and TNF- $\alpha$ (23). It is known that IL-18 alone stimulates the TH1-mediated immune response and thereby enhances the levels of two other pro-inflammatory essential factors - IL-6 and TNF- $\alpha$.

IL-1 is considered as one of the most important mediators of inflammatory responses, inducing a cascade of pro-inflammatory effector molecules. Studies show that its effect on the myocardium includes structural and functional changes in cardiomyocytes such as myocardial hypertrophy, regulation of MAP kinase pathway and induction of endothelial growth factor, etc (24). Studies not only establish elevated cytokine values in chronic heart failure, but also prove its involvement in the regulation of the systemic inflammatory response in CHF (25).

Pathophysiological processes in cardiomyopathies still continue to be a particular subject of interest. Just as in many other diseases, inflammation has also found its place. For instance, it is established that radiation-induced cardiomyopathy is associated with elevated levels of the proinflammatory cytokine IL-18 (26). Elevated levels of IL-6 are measured in peripartum cardiomyopathy (27). TNF- $\alpha$ and IL- 6 show an increase in idiopathic dilated cardiomyopathy (28).
Interleukin changes are also observed in cardiac arrhythmias. In experimental conditions the expression of ventricular tachycardia in acute myocardial infarction is associated with an increase in TNF- $\alpha$ values (29). It is known that it has pleiotropic biological effects associated with cell proliferation, differentiation, apoptosis and inflammatory reactions. Moreover, according to some studies it regulates the $\mathrm{Ca}^{2+}$ - flow and can induce electrical remodeling of the myocardium, which in the particular study could be the cause of the manifestation of the rhythm disorder. A study by Vasiletz et al. also found an increase of pro-inflammatory markers TNF- $\alpha$ and IL- 6 in expression of ventricular arrhythmias (30). Given the high incidence of atrial fibrillation (AF), the interleukin response in these patients is subject of numerous studies. According to Sid, the levels of IL- $1 \beta$ and TNF- $\alpha$ are significantly elevated in patients with permanent AF compared to surveyed controls without rhythm disorders, and the values of TNF- $\alpha$ are predictive for the manifestation of the arrhythmia (31). The author believes that the results are not only indicative of the presence of inflammation in permanent $\mathrm{AF}$, but are a major prerequisite to accept the participation of interleukins in the pathogenetic mechanisms of the disease. In postoperative AF the levels of pro-inflammatory interleukins IL-6 and IL-8 are elevated (32). The levels of pro-inflammatory IL-2 have also been researched, although in single studies. Its low values are associated with reduced incidence of postoperative $\mathrm{AF}$ and increased success rate of pharmacological cardioversion in recent-onset $\mathrm{AF}(33,34)$.

\section{CONCLUSIONS}

In conclusion we could say that in a number of cardiovascular diseases such IHD, CHF, some cardiomyopathies and arrhythmias, disorders in the interleukin status of the body are observed. Significantly altered are the levels of both pro-inflammatory and anti-inflammatory ILs. Some of the studied cytokines such as IL-18, TNF- $\alpha$, etc. have a predictive effect on the expression of a specific disease. The nature of the identified changes gives grounds to assume that interleukin response is not just an accidental finding, but is most likely connected to the intimate mechanisms of diseases. This certainly raises the question of how these research results can be 
transferred into clinical practice. The confirmation of some ILs as prognostic indicators and their acceptance as potential therapeutic targets, would change completely the clinical approach in these diseases.

\section{REFERENCES}

1. Aarden LA, Brunner TK, Cerottini JC, Dayer JM et al. Revised nomenclature for antigen-non-specific T cell proliferation and helper factors. J. Immunol. 1979 Dec;123(6):2928-9.

2. Khan MM, Immunopharmacology. Springer US; 2008.

3. Commins SP, Borish L, Steinke JW. Immunologic messenger molecules: cytokines, interferons, and chemokines. J Allergy Clin Immunol. 2010 Feb;125(2 Suppl 2):S53-72.

4. Brocker C, Thompson D, Matsumoto A, Nebert DW, Vasiliou V. Evolutionary divergence and functions of the human interleukin (IL) gene family. Hum Genomics. 2010;5(1):30-55.

5. AK Shrivastavaa, HV Singhb, A Raizadac, SK Singhd. C-reactive protein, inflammation and coronary heart disease. The Egyptian Heart Journal. 2015;67(2):89-97.

6. Oikonomou E, Tousoulis D, Siasos G, Zaromitidou M, Papavassiliou AG, Stefanadis C. The role of inflammation in heart failure: new therapeutic approaches. Hellenic J Cardiol. 2011;52(1):30-40.

7. Westermann D. Does inflammation trigger fibrosis in hypertrophic cardiomyopathy: a burning question? Heart. 2012;98(13):965-6.

8. Westermann $D$, Rutschow $S$, Jäger $S$, Linderer $A$, Anker S, Riad A, Unger T, Schultheiss HP, Pauschinger $\mathrm{M}$, Tschöpe $\mathrm{C}$. Contributions of inflammation and cardiac matrix metalloproteinase activity to cardiac failure in diabetic cardiomyopathy: the role of angiotensin type 1 receptor antagonism. Diabetes. 2007;56(3):641-6.

9. Klein RM, Vester EG, Brehm MU, Dees H, Picard F, Niederacher D, Beckmann MW, Strauer BE. Inflammation of the myocardium as an arrhythmia trigger. Z Kardiol. 2000;89 Suppl 3:24-35.

10. Galea J, Armstrong J, Gadsdon P, Holden H, Francis SE, Holt CM. Interleukin-1 beta in coronary arteries of patients with ischemic heart disease. Arterioscler Thromb Vasc Biol. 1996;16(8):1000-6.

11. Ozdemir O, Gundogdu F, Karakelleoglu S, Sevimli S, Pirim I, Acikel M, Arslan S, Serdar S. Comparison of serum levels of inflammatory markers and allelic variant of interleukin- 6 in patients with acute coronary syndrome and stable angina pectoris. Coron Artery Dis. 2008;19:15-9.

12. Commins SP, Borish L, Steinke JW. Immunologic messenger molecules: cytokines, interferons, and chemokines. Allergy Clin Immunol. 2010;125(2 Suppl 2):S53-72.

13. Blankenberg $S$, Luc G, Ducimetière $P$, Arveiler $\mathrm{D}$, Ferrières J, Amouyel P, Evans A, Cambien F, Tiret L; PRIME Study Group. Interleukin-18 and the risk of coronary heart disease in European men: the Prospective Epidemiological Study of Myocardial Infarction (PRIME). Circulation. 2003;108(20):2453-9.

14. RH Zhou, Q Shi, HQ Gao, BJ Shen. Changes in Serum Interleukin-8 and Interleukin-12 Levels in Patients with Ischemic Heart Disease in a Chinese Population. Journal of Atherosclerosis and Thrombosis. 2001;8:30-32.

15. Burke SM, Issekutz TB, Mohan K, Lee PW, Shmulevitz M, Marshall JS. Human mast cell activation with virus-associated stimuli leads to the selective chemotaxis of natural killer cells by a CXCL8-dependent mechanism. Blood 2008;111:5467-76.

16. Vaddi K, Nicolini FA, Mehta P, Mehta JL. Increased secretion of tumor necrosis factor-alpha and interferon-gamma by mononuclear leukocytes in patients with ischemic heart disease. Relevance in superoxide anion generation. Circulation. 1994;90(2):694-9.

17. Eid RE, Rao DA, Zhou J, Lo SF, Ranjbaran H, Gallo A, et al. Interleukin-17 and interferon-gamma are produced concomitantly by human coronary artery-infiltrating $\mathrm{T}$ cells and act synergistically on vascular smooth muscle cells. Circulation. 2009;119(10):1424-32.

18. Abdulkareem MK, Alderzi AR, Saeed BN. Interleukin- 8 and interleukin-10 in patients with ischemic heart disease. The Iraqi Postgraduate Medical Journal. 2013;12:suppl.

19. Rodríguez AD, Abreu González P, García González MJ, Ferrer Hita J. Association between serum interleukin 10 level and development of heart failure in acute myocardial infarction patients treated by primary angioplasty. Rev Esp Cardiol. 2005;58(6):626-30.

20. Nymo SH, Hulthe J, Ueland T, McMurray J, Wikstrand J, Askevold ET, Yndestad A, Gullestad L, Aukrust P. Inflammatory cytokines in chron- 
Mariya Negreva, Svetoslav Georgiev, Katerina Vitlianova

ic heart failure: interleukin-8 is associated with adverse outcome. Results from CORONA. Eur J Heart Fail. 2014;16(1):68-75.

21. Fairweather D, Frisancho-Kiss S, Yusung SA, Barrett MA, Davis SE, Gatewood SJ, Njoku DB, Rose NR. Interferon-gamma protects against chronic viral myocarditis by reducing mast cell degranulation, fibrosis, and the profibrotic cytokines transforming growth factor-beta 1, interleukin-1 beta, and interleukin-4 in the heart. Am J Pathol. 2004;165(6):1883-94.

22. Roselló-Lletí E, Rivera M, Bertomeu V, Cortés R, Jordán A, González-Molina A. Interleukin-4 and cardiac fibrosis in patients with heart failure. Rev Esp Cardiol. 2007;60(7):777-80.

23. Y Naito, T Tsujino, Y Fujioka, M Ohyanagi, H Okamura, and T Iwasaki. Increased circulating interleukin-18 in patients with congestive heart failure. Heart. 2002 Sep; 88(3):296-297.

24. Vicenová B, Vopálenský V, Burýsek L, Pospísek M. Emerging role of interleukin-1 in cardiovascular diseases. Physiol Res. 2009;58(4):481-98.

25. Van Tassell BW, Toldo S, Mezzaroma E, Abbate A. Targeting interleukin-1 in heart disease. Circulation. 2013;128(17):1910-23.

26. Mezzaroma E, Mikkelsen RB, Toldo S, Mauro AG, Sharma K, Marchetti C, Alam A, Van Tassell BW, Gewirtz DA, Abbate A. Role of interleukin-1 in radiation induced cardiomyopathy. Mol Med. 2015 Mar 26. doi: 10.2119/molmed.2014.00243. (Epub ahead of print).

27. Nakamura K, Itoh H, Sagawa N, Kakui K, Nakayama T, Yamada S, Fujii S. A case of peripartum cardiomyopathy with a transient increase of plasma interleukin- 6 concentration occurred following mirror syndrome. J Perinat Med. 2002;30(5):426-8.

28. Högye M, Mándi Y, Csanády M, Sepp R, Buzás K. Comparison of circulating levels of interleukin-6 and tumor necrosis factor-alpha in hypertrophic cardiomyopathy and in idiopathic dilated cardiomyopathy. Am J Cardiol. 2004;94(2):249-51.

29. Chen $Y$, Chen Z, Liao Y, Cao Z, Xia Y, Yang H, Du Y. Effect of tumor necrosis factor- $\alpha$ on ventricular arrhythmias in rats with acute myocardial infarction in vivo. World J Emerg Med. 2010;1(1):53-58.

30. Vasilets LM, Tuev AV, Agafonov AV, Ratanova EA, Krivaia AA, Trenogina KV, Grigoriadi NE. Ventricular arrhythmias and arterial hypertension: role of inflammatory biomarkers in arrhyth- mia development. Vestn Ross Akad Med Nauk. 2012;(10):12-7.

31. Sid EV. Predictor value cytokines for recurrence of arrhythmia in patients with coronary heart disease combined hypertension and persistent atrial fibrillation. Biological Markers and Guided Therapy. 2014;1(2):109-114.

32. Hadi AR Hadi, Alsheikh-Ali AA, Wael AL Mahmeed, Jassim M Al Suwaidi. Inflammatory cytokines and atrial fibrillation: current and prospective views. J Inflamm Res. 2010;3:75-97.

33. Pinto A, Tuttolomondo A, Casuccio A. Immuno-inflammatory predictors of stroke at follow-up in patients with chronic non-valvular atrial fibrillation (NVAF). Clin Sci (Lond). 2009;116:781-789.

34. Hak Ł, Myśliwska J, Wieckiewicz J, Szyndler K, Siebert J, Rogowski J. Interleukin-2 as a predictor of early postoperative atrial fibrillation after cardiopulmonary bypass graft (CABG). J Interferon Cytokine Res. 2009;29:327-332. 